\title{
COVID-19 E A PROTEÇÁO DOS REFUGIADOS: A ATUAÇÁO DOS ESTADOS EM ZONA DE CONFLITOS ARMADOS
}

\author{
Ana Carolina Santos Leal da Rocha Bernardes ${ }^{1}$ \\ Pontifícia Universidade Católica de Minas Gerais (PUC-MINAS) \\ Mário Lúcio Quintão Soares ${ }^{2}$ \\ Pontifícia Universidade Católica de Minas Gerais (PUC-MINAS) \\ Artigo recebido em: 21/07/2020. \\ Artigo aceito em: 01/10/2020.
}

\section{Resumo}

A crise dos refugiados tem preocupado cada vez mais os Estados, autoridades e organismos internacionais. Em meio a pandemia da Covid-19, doença respiratória transmitida facilmente entre os indivíduos, não podemos negligenciar aqueles que sobrevivem dia após dia em um campo de refugiados. $\mathrm{O}$ presente artigo teve como objetivo analisar como os Estados têm enfrentado a crise dos refugiados no contexto da pandemia. A pesquisa foi desenvolvida por meio de análise qualitativa e exploratória e foi aplicado o método dialético. Realizou-se, também, como parâmetro para a mediação do debate, a pesquisa bibliográfica e documental. Pode-se concluir que os refugiados têm sido cada vez mais negligenciados acerca de seus direitos fundamentais, pois têm se abrigado em campos para refugiados os quais náo seguem as orientaçôes de higiene recomendadas pela Organizaçáo Mundial de Saúde (OMS) para evitar a disseminação do vírus. Além disso, atitudes xenófobas têm sido continuamente demonstradas, bem como o fechamento de fronteiras em grande parte dos países do globo, para aqueles que abandonam seus lares em busca de uma vida digna, sem perseguiçóes, ameaças e perigos, em meio à pandemia.

Palavras-chave: Covid-19; Estados; refugiados.

1 Doutora em Direito Público Internacional pela PUC-MINAS. Mestre em Direito Público Internacional pela PUC-MINAS. Bacharel em Direito pela PUC-MINAS. Professora na PUC-MINAS, com ênfase nas áreas de Direito Internacional Público e Privado, Constitucional, Humano, Administrativo e do Trabalho. Advogada. E-mail: anacarolinar35@gmail.com

2 Doutor em Direito Constitucional pela Universidade Federal de Minas Gerais (UFMG). Mestre em Direito pela UFMG. Graduado em Direito pela UFMG. Professor de Direito Constitucional, Teoria Geral de Direito Público, Direito Comunitário e Teoria do Estado do bacharelado, mestrado e doutorado da Faculdade Mineira de Direito da PUC-MINAS. Advogado. ORCID: https://orcid.org/0000-0002-3582-3109 / e-mail: mlquintao@yahoo.com.br 


\section{COVID-19 AND THE PROTECTION OF REFUGEES: THE STATES PERFORMANCE IN THE AREA OF ARMED CONFLICTS}

\section{Abstract}

The refugee crisis has increasingly worried States, authorities and international organizations. In the midst of the Covid-19 pandemic, a respiratory disease easily transmitted among individuals, we cannot forget those who survive day after day in a refugee camp. This article aimed to analyze how States have faced the refugee crisis together with Covid-19. The research was developed through qualitative research, using the exploratory research technique and the dialectic method. Procedures for mediation of work, bibliographic research and documentary research were also carried out. It can be concluded that refugees have been increasingly neglected about their fundamental rights, as they have taken shelter in refugee camps who do not follow the hygiene guidelines recommended by WHO to prevent the spread of the virus. Furthermore, xenophobic attitudes have been continuously demonstrated, as well as the closing of borders in most countries of the globe, for those who leave their homes in search of a dignified life, without persecution, threats and dangers, in the midst of the pandemic.

Keywords: Covid-19; governments; refugees. 


\section{Introdução}

A questáo dos refugiados ganhou relevância no cenário internacional nos últimos anos. Imagens marcantes de refugiados sujeitos ao abandono, sofrimento, maus tratos e até mortes são manchetes diárias na mídia.

Todavia, deve-se ter em mente que o conceito de refugiado remete a pessoas que foram forçadas a abandonar seus lares, buscando uma expectativa de uma vida digna, segura e sem perseguiçóes em outras cidades ou países.

Esse conceito traz consigo várias características, tais como: expectativa do uso da força, erupção repentina de conflitos, o não desaparecimento definitivo destes, ocorrência de tréguas em determinados momentos e a necessidade de respostas rápidas ao conflito em situaçôes de agravamento de sua intensidade.

Com o advento do Protocolo Relativo aos Refugiados, de 1967, ocorreu uma atualização ao classificar um refugiado. São consideradas as pessoas que se encontram fora de seu país em razão do temor de perseguição, violaçáo de direitos humanos e conflitos armados.

O princípio do non-refoulement, com previsão na Convenção de 1951 e no Protocolo de 1967, aduz que nenhum país deve expulsar ou "devolver" (refouler) um refugiado, contra a vontade do mesmo, em quaisquer ocasióes, para um território onde ele ou ela sofra perseguiçáo.

Estudo realizado pela Harvard Medical School apontou o aparecimento do vírus entre outubro e novembro de 2019, na China (LIMÓN, 2020). Assim sendo, o ano de 2020 seria a segunda onda da Covid-19, nomeado pela OMS de SARS-CoV-2, que causa a doença Covid-19 (Corona Virus Disease), a qual vem apresentando altos índices de mortalidade, decorrentes de síndromes respiratórias agudas. Muitos dos sintomas vêm sendo diagnosticados, além de sequelas diversas no organismo. A Covid-19 infectou milhares de pessoas ao redor do mundo e, possivelmente, surgiu em Wuhan, uma província chinesa.

Medidas como isolamento, distanciamento social, quarentena e testes rápidos são tentativas realizadas no intuito de reduzir a disseminação do vírus. Porém, com o espalhamento deste globalmente, a situação agrava-se nos países em desenvolvimento, os quais possuem sistemas de saúde descompassados. Regióes em que os índices de mortalidade vêm alcançando patamares preocupantes, pois as medidas de contenção vêm demonstrando menor aplicabilidade e, portanto, menor eficácia.

O surto da Covid-19 expande a preocupação dos Estados, não só para com nacionais, mas em relação àqueles que se encontram em situação migratória nos territórios, em busca de uma melhor condição de vida para si e seus familiares. 
Xenofobia e discriminação são vocábulos frequentes quando se trata de refugiados. A responsabilidade de proteçáo dos Estados em face de seus cidadáos urge em tempos de pandemia. No entanto, se há uma desatenção por parte daqueles responsáveis por resguardar os direitos básicos, os refugiados sofrerão tais efeitos de maneira agudizada.

Organizaçóes internacionais alertam para a possibilidade de eventuais surtos de Covid-19 em campos de refugiados, uma vez que vivemos um momento de intensos intercâmbios migratórios gerados por conflitos territoriais de ordens diversas, sobretudo no Oriente Médio, e a capacidade dos referidos campos já chegou ao limite, consequentemente, há a dificuldade de se colocar em prova as recomendaçóes advindas da OMS no que tange a higiene.

O presente artigo visa examinar a maneira como os Estados têm enfrentado a pandemia e a garantia de direitos aos refugiados. Tal análise ocorreu por meio de pesquisa qualitativa e exploratória e o método aplicado foi o analítico dialético. Realizaram-se, também, procedimentos para a mediação do trabalho, como pesquisa bibliográfica documental.

\section{$1 \mathrm{O}$ conceito de refugiados}

O Alto Comissariado das Naçôes Unidas para os Refugiados (ACNUR) foi criado com missão de assegurar aos refugiados a aplicação dos protocolos internacionais, bem como a Convenção Relativa ao Estatuto dos Refugiados de 1951 e o Protocolo Relativo ao Estatuto dos Refugiados de 1967.

A Convenção Relativa ao Estatuto dos Refugiados vislumbrou como refugiado a pessoa que residia na Europa ou outros territórios e com marco temporal aduzido antes dos acontecimentos de $1^{\circ}$ de janeiro de 1951.

A referida restriçáo tornou-se muito simplista e reduzia a definição de refugiado. Era preciso mais. Fazia-se necessária uma definição que abarcasse todas as pessoas que se encontravam fora de seus lares por algum motivo e que não houvesse lapso temporal e geográfico.

Em 1967, com o advento do Protocolo Relativo ao Estatuto dos Refugiados, o conceito de refugiado trouxe uma ampliação em sua definição.

Para os fins do presente Protocolo, o termo "refugiado", salvo no que diz respeito à aplicação do $\$ 3$ do presente artigo, significa qualquer pessoa que se enquadre na definiçấo dada no artigo primeiro da Convenção, como se as palavras "em decorrência dos acontecimentos ocorridos antes de $1^{\circ}$ de janeiro de 1951 e...." e as palavras "...como consequência de tais acontecimentos" não figurassem do $\$ 2$ da seçấo $\mathrm{A}$ do artigo primeiro. $\mathrm{O}$ presente 
Protocolo será aplicado pelos Estados Membros sem nenhuma limitação geográfica; entretanto, as declaraçōes já feitas em virtude da alínea "a” do $\$ 1$ da seção B do artigo 1 da Convenção aplicar-se-ão, também, no regime do presente Protocolo, a menos que as obrigaçóes do Estado declarante tenham sido ampliadas de conformidade com o $\$ 2$ da seção B do artigo 1 da Convenção (ONU, 1967, p. 1).

Desse modo, houve a consolidaçáo do conceito de refugiado com o advento do Protocolo Relativo ao Estatuto de Refugiados, datado no ano de 1967 e com aplicação da definição: são as pessoas encontradas fora de seu país de origem em razão de fundados temores de perseguiçâo relacionados a questôes em matéria de raça, religiáo, nacionalidade, pertencimento a determinado grupo social ou opiniâo política e, além da grave e generalizada violaçáo de direitos humanos e conflitos armados (ONU, 1967, p. 1).

Por tal motivo, o conceito de refugiado, trazido pela Convenção de 51, não conferia efetiva proteção a muitas pessoas que se evadissem de seus países em virtude de perseguiçóes estatais. Mesmo com tais restriçóes, a Convençáo de 1951 trouxe consigo uma definiçẫo razoável de refugiado, uniformizou os requisitos para reconhecimento da condição de refugiado em âmbito mundial, e realçou o princípio do non-refoulement (SOARES, 2015, p. 162).

Presente em ambos os documentos internacionais, o princípio do non-refoulement estabelece que a segurança e a integridade física e psíquica do refugiado devem ser salvaguardadas e, portanto, nenhum refugiado pode ser devolvido ao seu país anterior ou encaminhado para um território onde possa sofrer perseguiçáo, correr risco de vida ou reencaminhado a um terceiro território onde sua vida ou integridade possam vir a ser ameaçadas.

[...] o sofrimento inarrável vivenciado por milhóes de criaturas humanas que sobreviveram à grande catástrofe do século XX, a Segunda Guerra Mundial (que ceifou a vida de mais de quarenta milhôes de pessoas), levou as Naçóes Unidas a elaborar uma das mais importantes convençóes internacionais, que regula a situação jurídica dos refugiados (BARBOSA; SAGRADO DA HORA, 2007, p. 17).

De acordo com o direito interno de cada Estado ou continente, a definição de refugiado poderá ser alterada, mas todas possuem um mesmo denominador comum: a Convenção Relativa ao Estatuto dos Refugiados de 1951 e o Protocolo 
Relativo aos Refugiados de 1967. Insta salientar o comprometimento dos Estados com a cooperaçáo internacional, realizada por meio de tratados, os quais exercem força constitucional, acordos e convenções para assegurar direitos e garantias individuais.

No Brasil, no que tange aos direitos e garantias fundamentais, ambos são considerados cláusulas pétreas, quais sejam: forma federativa de Estado; voto direito, secreto, universal e periódico; a separação dos poderes e os direitos e garantias individuais, previstos pela Constituição Federal de 1988. Ou seja, não podem ser objeto de deliberação do referido tópico para proposta de emenda.

Em 2016, o Brasil participou da Cúpula de Líderes sobre Refugiados e assumiu o compromisso humanitário de receber os refugiados sírios e inclui-los na sociedade por meio de programas sociais e agências de fomento, tais como o Programa Nacional de Acesso ao Ensino Técnico e Emprego (PRONATEC) e o Serviço Brasileiro de Apoio às Micro e Pequenas Empresas (SEBRAE), respectivamente.

Com o advento da Lei n. 13.445/2017, atualmente conhecida como Lei de Migração, a regularizaçáo migratória passou a ser a regra. Todos os estrangeiros, com propósito de migraçáo, que ultrapassarem as fronteiras nacionais terão de se apresentar perante a Polícia Federal para regularizar sua situação.

Aqueles integrantes de grupos vulneráveis e os indivíduos que forem constatados possuidores de hipossuficiência econômica serão isentos do pagamento das taxas e emolumentos consulares para concessão de vistos ou para obtenção de documentos para regularizar a situação migratória.

Ao tratarmos a questão dos refugiados em âmbito regional, há de se falar sobre a Declaração de Cartagena das Índias. O Colóquio de Cartagena foi celebrado sob os auspícios do Governo da Colômbia. A crise política em diferentes países da América Central havia causado a saída de refugiados em números sem precedentes nessa parte do mundo em direção a países vizinhos da América Central e também a países da regiáo centro-americana (TRINDADE; PEYTRIGNET; RUIZ DE SANTIAGO, 1996).

Em observância aos debates realizados no aludido Colóquio, levaram-se em consideração para a criação do conceito de refugiado na América Central a busca de uma vida digna e segura, a concessão de asilo, bem como a valorização dos direitos humanos e das diligências multilaterais em prol da manutenção da paz.

Nos anos de 1991 a 1994, a Organização dos Estados Americanos enviou esforços para adotar diretrizes sobre os refugiados em reunióes da Assembleia Geral, no intuito de garantir melhores condiçóes e direitos para os indivíduos provenientes de países localizados na América Central.

Na Declaração de San José e Pessoas Deslocadas, ocorrida entre 5 e 7 de 
dezembro de 1994, visou à cooperação internacional, entre Estados da América Latina e Caraíbas, em face dos refugiados e deslocados internos. Ressalta-se, ainda, o aprofundamento entre o Direito Internacional e os direitos humanos, uma vez que visivelmente existem pontos convergentes entre a declaração e os documentos internacionais. Barichello (2009, p. 60) disserta sobre os principais desafios acerca da proteçấo dos refugiados:

Com o objetivo de analisar conjuntamente os principais desafios que enfrentava a proteção dos refugiados e de outras pessoas necessitadas de proteção internacional na América Latina e de identificar linhas de açâo dentro dos princípios da Declaração de Cartagena, foram realizadas quatro reunióes consultivas preparatórias: em San José, Costa Rica, nos dias 12 e 13 de agosto; em Brasília, Brasil, nos dias 26 e 27 de agosto; em Cartagena das Índias, Colômbia, nos dias 16 e 17 de setembro e em Bogotá, Colômbia, nos dias 6 e 7 de outubro. Como resultado desses encontros, nos quais foi analisada a problemática dos refugiados em cada região, foram elaborados informes aprovados por consenso, que serviram de base para a elaboração da Declaraçáo e do Plano de Açăo do México, firmados em 16 de novembro de 2004, na cidade do México, por vinte países latino-americanos.

Durante a celebração dos 20 anos da Declaração de Cartagena das Índias, em novembro de 2004, foi admitida a Declaração e o Programa de Ação do México para fortalecer a Proteçấo Internacional dos Refugiados na América Latina. As medidas deliberadas na referida celebração foram a conceituação dos refugiados, a proteção e a superação dos obstáculos enfrentados por aqueles que abandonaram seus países e buscam uma vida digna e segura em outro território (ACNUR, 1984).

Por conseguinte, o direito dos refugiados e a obrigação dos Estados em assegurar-lhes direitos e garantias além dos que se encontram previstos na Convenção de 1951 e no Protocolo de 1967, se estendem para documentos internos e regionais, como o Pacto Internacional sobre Direitos Civis e Políticos e o Pacto Internacional sobre Direitos Econômicos, Sociais e Culturais que abarca uma legislação de aprimoramento para aquelas pessoas que se encontram em busca de uma vida digna fora de seu território.

Negar o acolhimento a refugiados pode acarretar consequências potencialmente mortais, por isso é importante esse reconhecimento internacional, para que tenham acesso a assistência dos Estados, do ACNUR e de organizaçóes relevantes (UNHCR, 2020; ONU, 1967). 
A imigração possui as mais diversas causas: muitos deixam seus países pela ocasiáo de conflitos armados, ocorrem perseguiçóes em virtude de raça, cor, sexo, nacionalidade além dos imigrantes provenientes de desastres naturais, também protegidos pelo ACNUR.

Quando um refugiado adentra em um território distinto do seu, alguns Estados fornecem prerrogativas como a da não expulsão; outros consentem em aplicar toda a legislação referente aos refugiados; outros apenas permitem a estadia dentro das tendas do ACNUR para que aguardem os trâmites da solicitação de refúgio.

A cada minuto milhares de pessoas são obrigadas a deixarem seus lares por causa de conflitos e perseguiçóes. Tais atos evidenciam a necessidade de um aprimoramento das respostas humanitárias advindas dos Estados.

Por abandonarem suas casas em busca de um lugar seguro, onde sejam capazes de ter proteção e o mínimo necessário de higiene e segurança, os refugiados têm sido um ponto relevante para a comunidade internacional. Com a Covid-19, muitos estão marginalizados e alijados de um local limpo, sem aglomeração e com água limpa para higiene básica. Os refugiados clamam por socorro.

\section{A Covid-19 e seu surgimento na comunidade internacional}

Em 31 de dezembro de 2019, a OMS fora alertada sobre diversos casos de uma pneumonia na província da Wuhan, na China. Após uma semana, no dia 7 de janeiro de 2020, as autoridades chinesas confirmaram que haviam identificado um novo tipo de vírus (OMS; OPAS, 2020). No dia 11 de março de 2020, a OMS, por intermédio de seu diretor-geral Thedros Adhanom, declarou que a pandemia do coronavírus e os Estados deveriam ser capazes de detectar, proteger, tratar e reduzir a transmissão do vírus.

Desde então, iniciou-se uma corrida contra o tempo em busca de uma vacina capaz de prevenir a contaminação pelo vírus. A contaminação desenfreada, a severidade dos casos e o impacto negativo na área da saúde afetam os países, principalmente os mais carentes em recursos, em suas esferas sociais e econômicas.

Percebemos os efeitos desproporcionais em determinados países, como o aumento do discurso de ódio, a segregação de grupos vulneráveis e os riscos de respostas de uma segurança pesada prejudicam a saúde coletiva. $\mathrm{Na}$ crescente onda do nacionalismo, do populismo e do autoritarismo, que vem sendo uma ameaça com a finalidade de desestabilizar os direitos humanos em determinados Estados, a crise pode fornecer um pretexto para 
adoção de medidas repressivas para questôes não relacionadas à pandemia. E isso é inaceitável (ONU, 2020, tradução livre)³.

Com a instauração da pandemia, cabe salientar o fechamento de fronteiras, a necessidade de repatriaçáo de nacionais por seus respectivos estados e o aumento da xenofobia e discriminação contra os estrangeiros. Necessário lembrar daqueles que vivem em países localizados em zonas de conflitos armados, pois estes não podem usufruir de distanciamento social, isolamento, água corrente e cuidados básicos de higiene, conforme já mencionado e recomendado pela OMS.

\subsection{A Covid-19 e os países em zona de conflito}

A pandemia do coronavírus sobrecarregou inclusive países que possuem aparatos médicos e sistema de saúde dos mais avançados, como os Estados Unidos, França e demais países da Europa, que possuem tecnologia e aparato médico o suficiente para suportar as demandas diárias em seus hospitais. Porém, com a chegada do coronavírus, estes passaram por escassez de UTI (Unidade de Terapia Intensiva) e equipamentos de proteção. Porém, países afetados por conflitos armados diários sequer têm o mínimo para começar o atendimento de seus habitantes.

A falta de suprimentos médicos para esses países não é o único desafio. Síria, Iêmen e Sudão do Sul, por exemplo, enfrentam diariamente questôes que perpassam desde os reflexos da crise sanitária proveniente do Covid-19 até conflitos e instabilidade política e econômica provocados pela pandemia.

Enquanto muitas zonas de conflito ainda não sentiram a força total do coronavírus, o tempo tem sido cada vez mais escasso. A seguir, veremos o exemplo de cinco estados, os quais convivem com a realidade diária da pandemia e dos conflitos armados. Esses Estados podem ser devastados pela Covid-19 caso medidas não sejam tomadas.

No Oriente Médio, os sírios presenciam momentos de tensão desde 2011 com a centralização do poder nas mãos do ditador Bashar Al-Assad e a atuação de grupos do Estado Islâmico que geram instabilidade no território e no cotidiano da populaçáo. A cada dia, milhares de nacionais abandonam a Síria em busca de um Estado seguro. Atualmente, com a disseminação do coronavírus na Síria pode ocorrer um dos mais graves surtos do mundo.

3 We see the disproportionate effects on certain communities, the rise of hate speech, the targeting of vulnerable groups, and the risks of heavy-handed security responses undermining the health response. Against the background of rising ethno-nationalism, populism, authoritarianism and a pushback against human rights in some countries, the crisis can provide a pretext to adopt repressive measures for purposes unrelated to the pandemic. This is unacceptable (ONU, 2020). 
Nove anos de conflitos internos deixaram o sistema de saúde da Síria em ruínas, com 85 unidades de saúde atacadas no norte do país apenas no ano passado. No Noroeste, onde os combates recentemente levaram ao maior deslocamento de civis de toda a guerra, existem apenas 105 leitos de UTI e 30 ventiladores adultos para uma população de 1,5 milhão. Quase todos já estão em uso. [...] A falta de comida, água potável e exposição ao clima frio já deixaram centenas de milhares de pessoas com problemas de saúde, tornando-as ainda mais vulneráveis a uma doença que podem se espalhar tão rapidamente quanto a Covid-19”, diz Misty Buswell, diretor regional de política e advocacia do Comitê Internacional de Resgate (International Rescue Commitee - IRC) ${ }^{4}$ (IRC, 2020, tradução livre).

Também localizado no Oriente Médio, após cinco anos de conflitos armados, o Iêmen enfrenta a maior crise humanitária do mundo. Em tempos de pandemia, apenas metade dos hospitais do Iêmen funcionam em sua totalidade e 18 milhôes de cidadãos iemenitas não têm sequer acesso a higiene, água e saneamento adequados.

Enquanto a coalizão liderada pela Arábia Saudita no Iêmen propôs recentemente um cessar-fogo de duas semanas, é urgentemente necessária uma cessação total da violência. [...] "Duas semanas não são tempo suficiente para preparar este país para os impactos devastadores que a Covid-19 terá, nem para alcançar os necessitados e aliviar seu sofrimento", disse Tamuna Sabedze, diretora do Comitê Internacional de Resgate (International Rescue Commitee - IRC) no país. "Não podemos controlar uma pandemia global entre bombas e ataques aéreos" 5 (IRC, 2020, tradução livre).

Noutro giro, situado no Continente Sul-Americano, a Venezuela enfrenta um cenário de fome, instabilidade e violência, o qual levou mais de 4,7 milhóes

4 "Nine years of conflict have left Syria's health care system in ruins, with 85 health facilities attacked in the north of the country just last year alone. In the northwest, where fighting recently led to the largest displacement of civilians of the entire war, there are just 105 ICU beds and 30 adult ventilators for a population of 1.5 million. Nearly all are already in use. [...] "A lack of food, clean water and exposure to cold weather has already left hundreds of thousands of people in poor health, making them even more vulnerable to a disease that can spread as quickly as COVID-19," says Misty Buswell, Middle East regional policy and advocacy director for the International Rescue Commitee (IRC) (IRC, 2020).

5 While the Saudi-led coalition fighting in Yemen recently proposed a two-week ceasefire, a full cessation of violence is desperately needed. "Two weeks is not enough time to prepare this country for the devastating impacts COVID-19 will have on the country, nor to reach those in need and alleviate their suffering," said Tamuna Sabedze, the IRC's Yemen country director. "We cannot control a global pandemic amongst bombs and airstrikes" (IRC, 2020). 
de pessoas a deixar seu território desde 2014 - entre elas, metade dos médicos do país.

Noventa por cento dos hospitais venezuelanos carecem de suprimentos básicos e existem apenas 84 leitos de UTI para uma população de 32 milhóes de venezuelanos. "Dentro da Venezuela, a situação é terrível", diz Marianne Menjivar, diretora do IRC na Venezuela e na Colômbia. Com as fronteiras agora fechadas para a Colômbia, outras turbulências econômicas ameaçam a vida de milhôes de venezuelanos ${ }^{6}$ (IRC, 2020, traduçâo livre).

O Sudão do Sul, país localizado ao centro do Continente Africano, vive mergulhado em um cenário de guerra e fome. Organizaçóes Internacionais como a Unicef e o ACNUR foram acionados para ajudar a contornar a situação humanitária desastrosa ilustrada pela fome e os habitantes que diariamente abandonam seus lares.

"O povo do Sudão do Sul já sofreu seis anos de terríveis guerras, fome e uma economia em colapso", diz Caroline Sekyewa, diretora do IRC no país. Menos da metade das unidades de saúde do país estão em pleno funcionamento e muitas em operação estão mal equipadas e com falta de pessoal. Com uma população de 11,7 milhōes de pessoas, o país possui apenas quatro ventiladores e 24 leitos de UTI. A interrupção dos programas humanitários que salvam vidas pela Covid-19 pode levar à fome no Sudão do Sul e em outros países com altos níveis de desnutrição ${ }^{7}$ (IRC, 2020, tradução livre).

País da África Ocidental, Burkina Faso, similar aos países localizados na África, possui um histórico de violência e conflitos armados. Seus nacionais se viram compelidos a abandonar suas casas, enquanto grupos armados lutam para consolidar sua presença no pequeno país. Burkina Faso, em meio a pandemia da Covid-19, possui apenas 11 ventiladores para sua população de 20,9 milhóes de pessoas.

6 Ninety percent of Venezuelan hospitals lack critical supplies, and there are only 84 ICU beds for a population of 32 million. "Inside of Venezuela, the situation is dire," says Marianne Menjivar, the IRC's country director for Venezuela and Colombia. With borders now closed to Colombia, further economic turmoil threatens the lives of millions of Venezuelans" (IRC, 2020).

7 "The people of South Sudan have already endured six years of terrible war, famine and a collapsed economy," says Caroline Sekyewa, South Sudan country director for the IRC. Less than half of the country's health facilities are fully functioning, and many in operation are poorly equipped and understaffed. With a population of 11.7 million people, the country has only four ventilators and 24 ICU beds. Disruption of lifesaving humanitarian programs by COVID-19 could lead to famine in South Sudan and other countries with high levels of malnutrition” (IRC,2020). 
"O aumento que Burkina Faso viu nos ataques de grupos armados no ano de 2019, agrava a dificuldade de mitigar a propagação de uma doença em uma área ativa de conflito, como vimos com o ebola na República Democrática do Congo”, diz Bob Kitchen, vice-presidente de emergências e açôes humanitárias do IRC. Uma nova análise pelo IRC do potencial impacto do coronavírus em zonas de crise mostra um quadro terrível. "A escala, gravidade e velocidade do surto de COVID-19 seráo ampliadas em países frágeis", diz o presidente e CEO do IRC, David Miliband, das conclusôes do relatório ${ }^{8}$ (IRC, 2020, traduçấo livre).

Miliband (apud IRC, 2020) ressalta, ainda, duas açóes essenciais para o combate à pandemia, em conjunto com estes passos urgentes primeiro, a atividade imediata para impedir a propagação da doença é imperativa. Sem instalaçóes de lavagem das máos, a doença se enraíza - e sem a triagem eficaz das pessoas, ela é abundantemente transmitida. Segundo ele, os elos mais fracos da cadeia global de saúde são uma ameaça à saúde em todos os lugares. Devemos fortalecer os esforços de prevenção em países devastados pela guerra e garantir que os refugiados e outras pessoas vulneráveis não sejam deixados para trás.

Caso haja uma falha advinda dos Estados, não somente os mais vulneráveis estarão sujeitos a consequências desastrosas, mas toda uma comunidade internacional, e os efeitos serão sentidos ao longo de décadas.

\section{O Alto Comissariado das Naçóes Unidas para os Refugiados (ACNUR) e as medidas de ingresso nos Estados em tempos de Covid-19}

A necessidade de proteção e garantia dos direitos fundamentais tornou-se maior em tempos de combate à Covid-19. Ao mencionarmos as dificuldades de aplicação dos métodos de higiene preconizados pela OMS, não podemos negligenciar a proteçáo aos refugiados, deslocados internos, apátridas e migrantes. Essa população é vulnerável à contaminação pelo vírus.

Em face à pandemia, o ACNUR, cujo mandato de proteção que inclui náo somente os refugiados, mas aqueles grupos citados anteriormente, publicou um informativo para orientar os países acerca do acesso por aqueles que têm diariamente seus direitos violados e buscam uma vida digna.

8 "The major increase Burkina Faso has seen in attacks by armed groups over the past year compounds the difficulty of mitigating the spread of a disease in an active conflict area, as we've seen with Ebola in the Democratic Republic of Congo," says Bob Kitchen, IRC vice president of emergencies and humanitarian action. New analysis by the IRC of the potential impact of the coronavirus in crisis zones paints a dire picture. "The scale, severity and speed of the COVID-19 outbreak will be magnified in fragile countries," says IRC president and CEO David Miliband of the report's findings. "The double crisis needs a double response" (IRC, 2020). 
Tal documento atém-se ao fato de que tais grupos necessitam de proteção e assistência internacional em razão dos riscos de contaminação durante a pandemia. Ressalta também a autonomia dos Estados em realizar a triagem daqueles interessados a adentrar em seu território. A medida não pode negar a solicitação de asilo ou resultar na expulsão do território em comento.

Medidas razoáveis para determinar e gerenciar riscos à saúde pública que possam surgir em conexão com pessoas que chegam de outros países podem incluir limitaçóes temporárias de movimento por um período limitado. Tais restriçôes devem, contudo, estar em conformidade com a lei, necessárias para o propósito legítimo de gerenciar o risco à saúde identificado, proporcional e sujeito a revisão regular9 (UNHCR, 2020, tradução livre).

Quando tais restriçôes equivalem à detenção, esse ato arbitrário ou discriminatório deve estar autorizado por lei, conforme as salvaguardas processuais aplicáveis, por um período de tempo limitado e em conformidade com os padróes internacionais. As preocupaçôes com a saúde não justificam o uso sistemático de detenção de imigração contra indivíduos ou grupos de requerentes de asilo ou refugiados (UNHCR, 2020).

Embora essas medidas de saúde pública possam não visar especificamente as pessoas que procuram proteção internacional, elas podem ter consequências de longo alcance para essas pessoas. Criar medidas para proteger a saúde pública pode afetar pessoas que buscam proteção internacional. Essas açóes podem ser o resultado de uma triagem de saúde, quarentena ou isolamento social.

Ressalta-se a necessidade de conformidade com o Direito Internacional, pois negar a entrada ao território poderia contribuir ainda mais para a disseminaçáo do vírus.

Em 17 de março de 2020, o Governo Federal publicou a portaria n. 120, a qual restringe, excepcional e temporariamente, em tempos de pandemia, a entrada de venezuelanos em território brasileiro, conforme recomendação da Agência Nacional de Vigilância Sanitária (Anvisa), sob a justificativa de agravar os riscos de contaminação pelo coronavírus.

$\mathrm{O}$ art. $6^{\circ}$ da portaria preconiza, em caso de descumprimento, a responsabilização civil, administrativa e penal do agente infrator, a deportação imediata do agente infrator e a inabilitação de pedido de refúgio.

\footnotetext{
9 Reasonable measures to ascertain and manage risks to public health that could arise in connection with people arriving from other countries could include temporary limitations on movement for a limited period. Such restrictions must however be in accordance with the law, necessary for the legitimate purpose of managing the identified health risk, proportionate, and subject to regular review (UNHCR, 2020).
} 
A referida legislação salienta a dificuldade do Sistema Único de Saúde (SUS) em receber tais estrangeiros infectados e contribuir na proliferação da Covid-19. Apesar do mundo inteiro reunir esforços para combater o coronavírus, não podemos negligenciar as necessidades dos milhares de refugiados e migrantes, não só venezuelanos, mas aqueles presentes ao redor de todo o globo.

\section{Conclusão}

Especialistas de saúde pública, bem como a OMS, concordam acerca da diminuição de circulação para frear a circulação do coronavírus. Entretanto, o fechamento de fronteiras nacionais náo pode ser observado sob a ótica de uma proteção mais efetiva.

Os direitos humanos não podem ser deixados à mercê da comunidade internacional, uma vez que cabe aos Estados a adoção de políticas públicas inclusivas para refugiados, migrantes, deslocados internos e todo aquele grupo de pessoas as quais necessitam de uma efetiva proteção advinda de organizaçôes internacionais em conjunto com os países.

A supressáo desses direitos colocou-se em voga dada a pandemia da Covid-19 e evidenciou ainda mais a falta de estrutura em termos médicos e hospitalares em diversos países do globo.

A permissão para viverem em campos de refugiados, onde existem apenas lonas brancas, com o símbolo do ACNUR e da ONU, com milhares de pessoas aglomeradas sob elas, não configura uma proteção efetiva aos refugiados. Em um cenário em que a recomendação da OMS é evitar o deslocamento e manter o distanciamento social, os refugiados não têm o mínimo de acesso a cuidados essenciais destinados a higiene básica.

A pandemia se alastrou por todos os continentes. Fronteiras têm sido recorrentemente fechadas e países se negam receber aqueles que buscam o ínfimo no que tange a sua proteçáo.

Por fim, salienta-se a necessidade de saúde pública para todos os grupos já mencionados: apátridas, deslocados internos, migrantes e refugiados. Com o passar dos dias, os campos de refugiados têm trabalhado com sua lotação máxima. Caso a Covid-19 adentre um desses campos e infecte os refugiados, os estados terão de lidar com essa conta. Os direitos humanos são direitos de todos. $\mathrm{E}$ cabe aos países signatários garantirem sua eficácia para todos e em prol de todos. 


\section{Referências}

ACNUR - ALTO COMISSARIADO DAS NAÇÓES UNIDAS PARA OS REFUGIADOS. Declaração de Cartagena. Colóquio sobre Proteçáo Internacional dos Refugiados na América Central, México e Panamá: Problemas Jurídicos e Humanitários. Cartagena das Índias, 22 nov. 1984. Disponível em: https://www. acnur.org/fileadmin/Documentos/portugues/BD_Legal/Instrumentos_Internacionais/Declaracao_de_Cartagena.pdf?view=1. Acesso em:1 jul. 2020.

ACNUR - ALTO COMISSARIADO DAS NAÇÓES UNIDAS PARA OS REFUGIADOS. Declaração de San José sobre Refugiados e Pessoas Deslocadas. San José, 5-7 dez. 1994. Disponível em: http://pfdc.pgr.mpf.mp.br/atuacao-e-conteudos-de-apoio/legislacao/asilos-refugiados-e-apatridas/declaracao-de-sao-jose-sobre-refugiados-e-pessoas-deslocadas-1994. Acesso em: 20 out. 2020.

BARBOSA, L. P. SAGRADO DA HORA, J. R. A polícia federal e a proteção internacional dos refugiados. Brasília, DF: ACNUR, 2007.

BARICHELLO, S. E. F. M. Direito Internacional dos refugiados da América Latina: o plano de ação do México e o Vaticínio de Hannah Arendt. Dissertação (Mestrado em Direito) - Universidade Federal de Santa Maria, Santa Maria, 2009.

BRASIL. Constituição (1988). Constituição da República Federativa do Brasil. Brasília, DF: Senado Federal: Centro Gráfico, 1988.

BRASIL. Lei n. 13.445, de 24 de maio de 2017. Institui a lei de migração. Diário Oficial da União - Seção 1 - 25/5/2017. Disponível em https://www2.camara. leg.br/legin/fed/lei/2017/lei-13445-24-maio-2017-784925-publicacaooriginal-152812-pl.html. Acesso em: 30 jun. 2020.

BRASIL. Portaria n. 120, de 17 de março de 2020. Dispóe sobre a restrição excepcional e temporária de entrada no País de estrangeiros oriundos da República Bolivariana da Venezuela, conforme recomendação da Agência Nacional de Vigilância Sanitária - Anvisa. Diário Oficial da União, Brasília, 18 mar. 2020. Disponível em: http://www.in.gov.br/en/web/dou/-/portaria-n-120-de-17-de-marco-de-2020-248564454. Acesso em: 30 jun. 2020.

Declaração de San José de 1994. Disponível em:

IRC - INTERNATIONAL RESCUE COMMITTEE. 5 crisis zones threatened by a coronavirus double emergency. Rescue.org, 9 abr. 2020. Disponível em: https://www.rescue.org/article/5-crisis-zones-threatened-coronavirus-double-emergency. Acesso em: 30 jun. 2020. 
JOHNS HOPKINS UNIVERSITY. Coronavirus Resource Center. COVID-19 Dashboard by the Center for Systems Science and Engineering (CSSE) at Johns Hopkins University (JHU). Baltimore: JHU, 2020. Disponível em: https://coronavirus.jhu.edu/map.html. Acesso em 30 jun. 2020.

LIMÓN, R. Estudo de Harvard indica que o coronavírus começou a circular em Wuhan em agosto, meses antes de surto. El Pais, 9 jun. 2020. Disponível em: https://brasil.elpais.com/ciencia/2020-06-09/estudo-de-harvard-indica-que-o-coronavirus-comecou-a-circular-em-wuhan-em-agosto-meses-antes-do-surto. html. Acesso em: 21 out. 2020.

OMS - ORGANIZAÇÃO MUNDIAL DA SAÚDE; OPAS - ORGANIZAÇÃO PAN-AMERICANA DA SAÚDE. Folha informativa - COVID-19. Brasília, DF: OMS/OPAS, 2020. Disponível em: https:/www.paho.org/bra/index. php?option=com_content $\&$ view $=$ article $\&$ id $=6101$ :Covid $19 \&$ Itemid $=875$. Acesso em: 2 jul. 2020.

ONU - ORGANIZAÇÃO DAS NAÇÕES UNIDAS. Convenção sobre o Estatuto do Refugiado. [S.1.]: ONU, 1951. Disponível em: http://www.acnur.org/t3/fileadmin/Documentos/portugues/BDL/Convencao_relativa_ao_Estatuto_dos_Refugiados.pdf?view=1. Acesso em: 4 jul. 2020.

ONU - ORGANIZAÇÃO DAS NAÇÓES UNIDAS. Protocolo sobre o Estatuto dos Refugiados. [S.l.]: ONU, 1967. Disponível em: http://www.adus.org.br/protocolode-1967-relativo-ao-estatuto-dos-refugiados/. Acesso em: 4 jul. 2020.

ONU - ORGANIZAÇÃO DAS NAÇÓES UNIDAS. COVID-19 and human rights: we are all in this together. New York: ONU, 2020. Disponível em: https:// www.un.org/en/un-coronavirus-communications-team/we-are-all-together-human-rights-and-Covid-19-response-and. Acesso em: 24 set. 2020.

SOARES, M. L. Q. A saga dos refugiados sob a égide do direito internacional, em tempo de globalização. Revista Duc In Altum - Cadernos de Direito, Recife, v. 7, n. 13, set./dez. 2015.

TRINDADE, A. A. C.; PEYTRIGNET, G.; RUIZ DE SANTIAGO, J. As três vertentes da proteçáo internacional dos direitos da pessoa humana: direitos humanos, direito humanitário e direito dos refugiados. San José; Brasília: ACNUR/CICV/ IIDH, 1996.

UNHCR - UNITED NATIONS HIGH COMMISSIONER FOR REFUGEES. Key legal considerations on access to territory for persons in need of international protection in the context of the COVID-19 response. Refworld, 16 mar. 
2020. Disponível em: https://www.refworld.org/docid/5e7132834.html. Acesso em: 1 jul. 2020. 